\section{A method of programming concurrent response opportunity on FI schedules with changeover holdoffs}

JOHN N. COULBOURN, IEHIGH VALLEY ELECTRONICS, INC., Fogelsville, Pennsylvania 18051

In the past it has been difficult to "lockout" or hold off the accumulation of time on one of two "concurrent" interval schedules while the $\mathrm{S}$ was responding on the other key. When it was behaviorally important not to allow both FI schedules to simply accumulate time concurrently, changeover contingencies, such as delays or resets to time zero of the interval on the inactive key, were introduced. When these were untenable in the experimental design and a holdoff or disjoint accumulation of time on only the active key became necessary, the solution proposed was to use two steppers, a time base and an alternator. When a "first" response was made on operandum " $L$," the alternator would go to that side, and further responses on that side would be redundant, keeping the alternator on Side "L." In this state (L), the alternator would switch time-base pulses to Side " $L$," allowing the " $L$ " stepper to increment toward the end of the interval. When a changeover was made to responding on operandum " $R$," the first response would cause the alternator to go to its " $R$ " state, gating off the time-base pulses to the "L" stepper and on to the " $R$ " stepper. Subsequent responses on " $R$ " would be, as before, redundant. Thus, the interval which was "active," or progressing toward the state of reinforcement availability, would be the one on which the most recent response was made and the other would be "locked out" or "holding."

The difference between this schedule and an ordinary concurrent $\mathrm{FI}$ is that when the animal is responding on one key he cannot accumulate "time toward reinforcement" on the other. When a changeover back to the other key is made, reinforcement is no more probable or imminently available than when the key was left.

The stepper method of changeover holding or lockout has obvious limitations of resolution and range. For example, if one of the intervals is $100 \mathrm{sec}$ and the program is accomplished by using a 10-point stepper and a 10-sec time base, then there may be a "behavioral advantage" in changeover of as much as $10 \mathrm{sec}$ accumulation of time on the "unused" key.

Using a Lehigh Valley Electronics 253-21 Universal Timer, such holdoffs are easily accomplished with a resolution better than the accuracy of the timer and with a direct range of from $.3 \mathrm{sec}$ up to $6 \mathrm{~h}$. The application of $-28 \mathrm{~V}$ to the HOLD input of the timer will stop the "red timing pointer" where it is for the duration of the signal.

In the program below (Fig. 1), Points "L" and " $R$," the pulse-formed responses from the left and right keys, are differentiated by going into the alternator from the two sides, and from the common to the operate. ${ }^{1}$ The first response to come in on the side to which the alternator is set will cause it to go to the other side, and subsequent responses on that side will be ignored. This operationally defines the active key as the one on which the most recent response was made. The top set of contacts on the alternator are used to apply a $-28-\mathrm{V}$ signal to the hold input of the inactive key's timer, thus achieving the holding function.

When a reinforcement is dispensed by the reinforcement pulse former, both timers receive a start pulse. The one at rest (timed out), which made the reinforcement available, will be restarted; and the other, which is in the holding mode, sees the pulse as redundant since it has started, begun timing, and is holding.

Since the hold function is an active dc brake circuit on the timer motor, the stop is instantaneous. This method of programming hold functions makes the FI temporal contingencies totally disjoint and changeovers offer no advantages in reinforcement probability or density.

\section{NOTE}

1. A two-relay holding circuit may be substituted for the alternator with one response going to "make" and the other to "break."

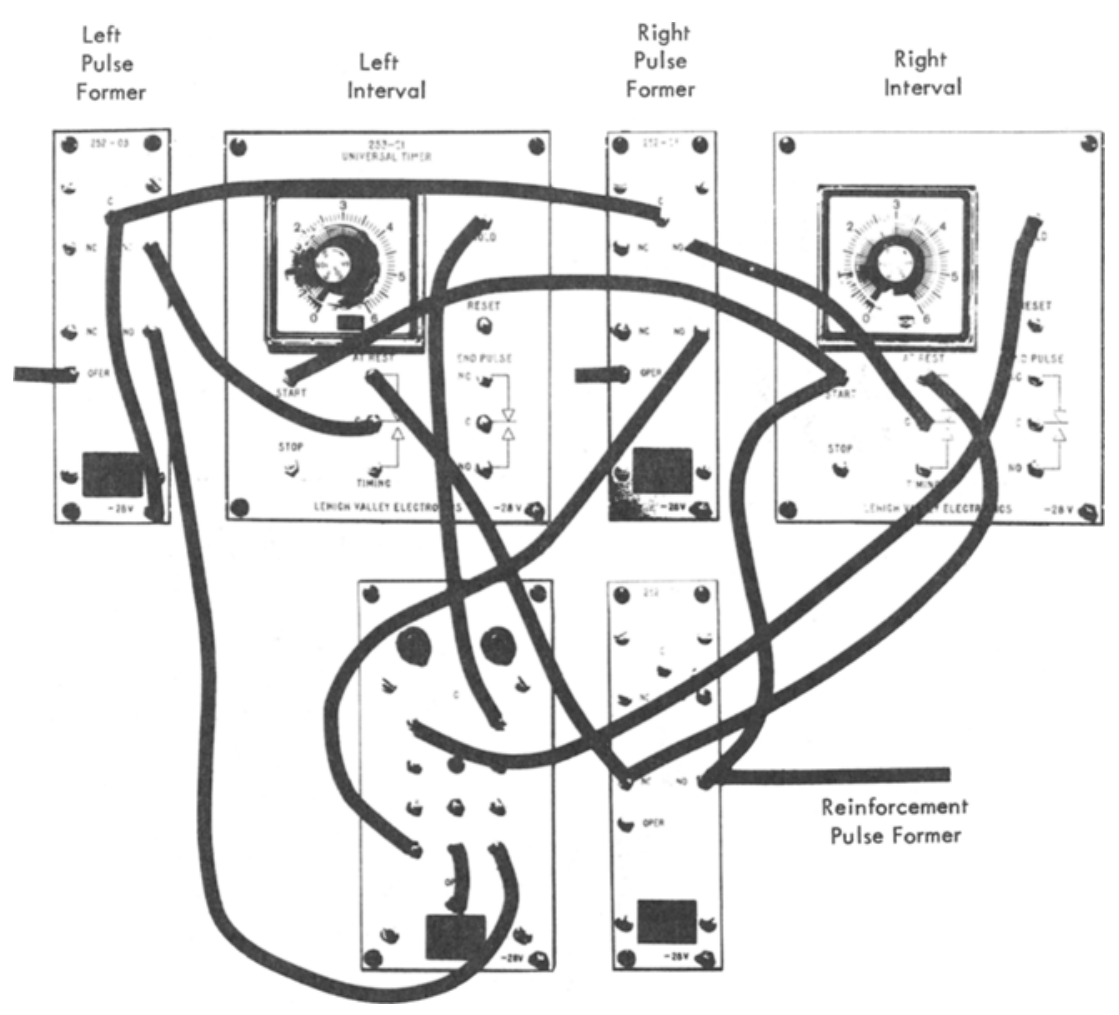

Fig. 1 Connections for interfacing modules noted in text. 